\title{
O FGTS e o mercado de títulos de base imobiliária: relações e tendências
}

\author{
FGTS and the market of real estate-backed \\ securities: relationships and trends \\ Luciana de Oliveira Royer
}

\section{Resumo}

0 artigo pesquisa as relações entre o Fundo de Garantia do Tempo de Serviço e os títulos creditícios de base imobiliária. As contratações efetuadas com recursos do FGTS a partir de 2008 para compra de títulos de base imobiliária acabaram por alavancar o mercado desses títulos no país, constituindo-se em um mecanismo gerador de uma liquidez mínima para seu funcionamento. A lógica do investimento nesses fundos é a lógica da valorização e do retorno do investimento, sem que exista necessariamente foco em uma política pública de habitação e desenvolvimento urbano voltada à universalização de direitos. É discutida a disputa pelos recursos do fundo e seu papel como um player desse mercado, no contexto da inserção do Brasil no capitalismo financeirizado.

Palavras-chave: financiamento habitacional; títulos creditícios de base imobiliária; FGTS; financeirização.

\begin{abstract}
The article describes the relationships between the FGTS and real estate-backed securities. FGTS is the Brazilian government's Severance Indemnity Fund: the employer deposits $8 \%$ of a worker's salary into the fund and this is managed by the federal government. Since 2008, contracts undertaken with FGTS resources for the acquisition of real estatebacked securities have stimulated the real estate bonds and securities market in Brazil, constituting a mechanism that generates a minimum liquidity for its own operation. The investment logic of real estate funds is the logic of investment return and gain, without necessarily focusing on a housing and urban development public policy geared towards the universalization of rights. The dispute over FGTS resources and its role as a player in this market are discussed in the context of Brazil's inclusion in financial capitalism.
\end{abstract}

Keywords: housing finance; real estate-backed securities; FGTS; financialization. 


\section{Introdução}

0 estudo sobre crédito, funding e arquitetura financeira se mostra fundamental para quem se dedica ao tema das cidades e do urbano em geral. 0 debate sobre o financiamento do desenvolvimento urbano, sempre sob a perspectiva da universalização dos direitos em um país com a desigualdade estrutural como o Brasil, é um dos pontos cruciais para a estruturação e a gestão de políticas públicas urbanas.

A utilização dos recursos dos chamados fundos parafiscais, o SBPE e o FGTS, Sistema Brasileiro de Poupança e Empréstimo e Fundo de Garantia do Tempo de Serviço, deve ser assim um ponto importante do debate sobre 0 assunto. Em especial o investimento do FGTS, fundo que historicamente tem conseguido atingir parte da renda média e parte da baixa renda no crédito habitacional e é responsável por importantes investimentos em infraestrutura urbana, deve ocupar um papel central na análise e pesquisas sobre o tema do financiamento público da infraestrutura urbana.

0 artigo está desenvolvido em quatro tópicos, além da introdução. Na primeira parte, será apresentado brevemente o contexto atual do crédito imobiliário no Brasil. Na sequência, discute-se a criação do FGTS, suas mudanças recentes, seu desempenho, procurando traçar um breve histórico do Fundo.

Para poder discutir a entrada do FGTS no mercado de títulos, a terceira parte do artigo procura introduzir alguns aspectos da evolução recente de títulos de base imobiliária no Brasil. Algumas de suas características básicas, bem como seu desempenho recente, são tratadas nesse tópico. 0 papel relevante que o FGTS tem nesse mercado é o tema da quarta parte do artigo, que trata da relação entre o Fundo e os títulos de base imobiliária.

Por fim, nas considerações finais, procura-se estabelecer alguns pontos para a reflexão a partir do volume de investimentos recentes do Fundo e as tendências que podem ser observadas a partir desses investimentos.

\section{Crédito e crédito imobiliário no Brasil}

0 crédito imobiliário vem aumentando sua participação no PIB de forma consistente e vem respondendo por uma parcela crescente do desempenho das operações de crédito no país, de acordo com o Relatório do Banco Central de 2013: "O crédito com recursos direcionados continuou a expandir em seus principais segmentos, com destaque para a aceleração do crédito rural e para a manutenção do ritmo de crescimento dos financiamentos imobiliários e dos investimentos com recursos do Banco Nacional de Desenvolvimento Econômico e Social (BNDES)". 1

A participação do crédito imobiliário nas operações de crédito e sua crescente importância podem ser melhor visualizadas ao se atentar para o volume de recursos das operações de crédito imobiliário (saldo da carteira de crédito com recursos direcionados pessoas jurídicas - financiamento imobiliário total): de 9,2 bilhões de reais em dezembro de 2008 para 66,2 bilhões de reais em dezembro de 2014. 0 volume movimentado pelo crédito direcionado para pessoas físicas (financiamento imobiliário total) também cresceu 
Gráfico 1 - Saldo operações de crédito ao setor imobiliário em relação ao PIB

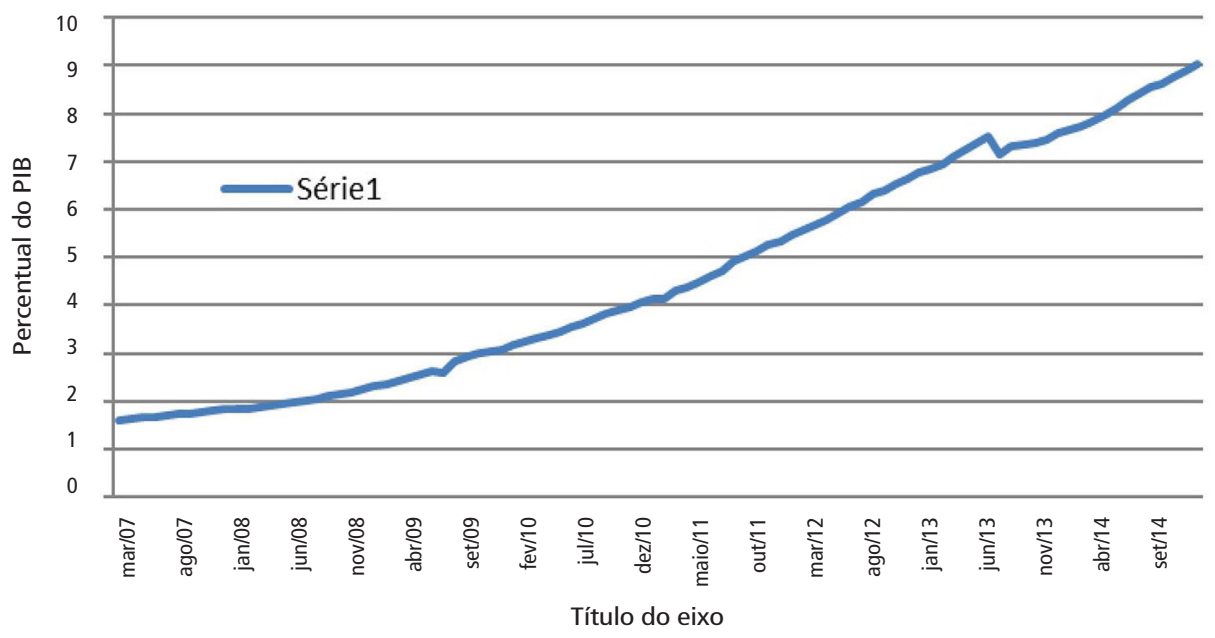

Fonte: Elaboração própria. Sistema Gerenciador de Séries Temporais do Banco Central do Brasil.

consideravelmente no período: de um saldo de 59,7 bilhões em dezembro de 2008 foi para 431,7 bilhões de reais em dezembro de 2014. 0 Gráfico 1 ilustra esse crescimento na relação do crédito imobiliário/ PIB.

A relação entre o crédito imobiliário e o PIB, apesar do consistente crescimento, ainda é considerada baixa se for comparada com outros países. Todo o chamado arcabouço regulatório permitiu uma expansão desse crédito de forma a mitigar e minimizar os riscos inerentes a uma operação de longo prazo junto aos agentes financeiros (Royer, 2014). E, principalmente, o que tem garantido a expansão sustentada desse crédito e a viabilidade das operações é o funding de crédito direcionado: caderneta de poupança (SBPE) e o FGTS (Royer, 2014; Magalhães Eloy, 2015).

\section{Breve histórico do FGTS}

Ao analisar o FGTS, percebe-se que sua constituição e seu desempenho ao longo dos quase 50 anos de existência o transforma em um patrimônio do trabalhador de fato, como é afirmado em muitos dos seus documentos oficiais (Brasil, MTE, 2015) e como veremos adiante.

A constituição de um fundo que pudesse ser uma alternativa à estabilidade no emprego, obrigatória no Brasil até a existência do FGTS² e também que pudesse financiar parte da infraestrutura urbana em um país que começava a apresentar persistentes taxas de urbanização parecia uma saída quase mágica para resolver dois problemas de uma só vez. 0 financiamento da indústria da construção civil era um problema relevante para a agenda pós-1964, 
e o BNH atuou diretamente nesse setor. 0 viés existente no BNH de uma política de incentivo industrial, constituindo um fundo robusto para dar suporte à indústria da construção civil nacional, foi estudado por importantes autores (Maricato, 1987).

Em 1965, a presidência do Banco Nacional de Habitação foi substituída por equipes ligadas ao Ministério da Fazenda e do Planejamento, que aceleraram as medidas necessárias para a implementação do modelo americano de crédito imobiliário. A concepção financista se tornou hegemônica, e a orientação a ser seguida no funcionamento do sistema, cada vez mais nítida. A Lei $n^{\circ} 4.864$, de novembro de 1965, que criou "medidas de estímulo à construção civil", ${ }^{3}$ é um exemplo do que o governo pretendia com a instituição de um sistema financeiro destinado à habitação: incentivos tributários como a isenção de IPI para "preparações e blocos de concreto", normatização de índices e outros instrumentos para a correção monetária de prestações e saldos devedores, independente se os financiamentos encontravam-se ou não no âmbito do SFH, mudança nos limitadores para aplicação dos recursos: $60 \%$ dos recursos aplicados em habitações de valor unitário inferior a 300 salários mínimos (na Lei $\mathrm{n}^{\circ} 4.380$, de 21 de agosto de 1964, que havia instituído o BNH, esse limite era de 100 salários); $20 \%$ dos recursos aplicados em habitações de valor unitário superior a 400 salários mínimos (na lei do BNH esse limite era 250 salários). A Lei $n^{\circ} 4.864$ permitiu também ao Banco Central autorizar as sociedades de crédito e financiamento a se transformar em sociedades de crédito imobiliário ou a manter carteira especializada nas operações próprias das sociedades de crédito imobiliário, incentivando dessa forma essas instituições a operar em um sistema integrado de associações de poupanças e empréstimos.

Os recursos iniciais destinados ao $\mathrm{SFH}$ e previstos na lei de criação do BNH/SFH eram oriundos de uma contribuição de $1 \%$ incidente sobre salários e também de subscrição compulsória de letras imobiliárias emitidas pelo BNH por locadores de imóveis com área superior a $160 \mathrm{~m}^{2}$, por institutos de previdência, SESC, Sesi, Caixas Econômicas e promotores da construção de imóveis com valor entre 1.000 e 2.000 salários mínimos, além de recursos subscritos pela União. No entanto, mesmo depois de um ano de instituído o SFH, os recursos ainda não haviam constituído um caixa significativo que pudesse dar um mínimo de escala na produção de unidades habitacionais e com isso fomentar a indústria da construção civil, um dos objetivos prioritários do sistema.

Foi de fato a constituição de um fundo parafiscal como o FGTS, por meio da Lei no. 5.107, de 13 de setembro de 1966, ${ }^{4}$ que deu outro impulso aos recursos antes restritos com os quais operava o Banco. O FGTS é um fundo financeiro formado pela contribuição mensal de empregadores aos seus empregados mediante depósito de $8 \%$ das remunerações em conta vinculada, ${ }^{5}$ de natureza privada e sob gestão pública, conformando uma poupança compulsória do trabalhador que o empregador recolhe na fonte. A magnitude dos recursos do FGTS alçou o BNH à condição de segundo estabelecimento bancário do país de sua criação até o início dos anos 70 por conta da aplicação e liquidez de seus recursos. ${ }^{6}$

Essa mudança de perfil, portanto, se daria exclusivamente pela origem financeira do dinheiro que comporia a base dos recursos a 
ser utilizado na execução da política, tal era a visão vigente à época do sistema, que prezava pelo equilíbrio econômico-financeiro e pela constituição do sistema como um fim em si mesmo. Dessa forma, ao mudar a origem do recurso que compunha o funding da política, muda também seu caráter, o que, se por um lado atenta para a necessidade de liquidez e solvabilidade dos recursos do sistema, por outro demonstra a preocupação em utilizar os fundos e seus recursos com quem tivesse capacidade financeira para isso, ou seja, financiar quem podia pagar. Recursos orçamentários não eram utilizados para a execução dos programas, nem a título de subsídio, o que ampliava o caráter regressivo da política. $\mathrm{O} \mathrm{BNH}$ responderia a essa dificuldade desenhando programas que continham subsídios internos bem como programas que tivessem juros mais altos, como os programas de cooperativas e mercado de hipotecas. Além disso, alguns programas contavam também com subsídios cruzados nos quais famílias de renda um pouco mais alta subsidiavam famílias de renda menor.

De fato, o desempenho do FGTS ao longo do período de funcionamento do BNH assegurou excelentes resultados quantitativos, demonstrando que essa fonte de recursos era de crucial importância tanto do ponto de vista do custo de captação do recurso para a execução de política habitacional para renda média e média baixa, quanto do fomento à indústria da construção civil. Atualmente podemos verificar que esse desempenho voltou a apresentar números muito significativos: em 2014, somente em habitação, o FGTS contratou 51,8 bilhões de reais (financiamentos e subsídios) perfazendo mais de 374,5 mil unidades naquele ano (dados Agente Operador FGTS).
Com a extinção do BNH em 1986 e da migração de sua carteira de financiamentos e do controle e operação do FGTS para a Caixa Econômica Federal, extinguiu-se também o Conselho Curador do FGTS. A hiperinflação e o cenário macroeconômico de fato impactaram no número de financiamentos feitos pelo fundo depois de 1986.

Um ponto de inflexão importante para compreendermos as escolhas atuais de investimento do FGTS se deu na era pós-Collor. Ainda no governo Sarney, como nos conta Schvasberg (1993), o Conselho Curador foi reestruturado, contando com a presença de representantes dos trabalhadores, empresários e governo. Essa reestruturação levou para o Conselho Curador as tensões do período, em especial quanto à distribuição territorial dos recursos do Fundo.

A retomada das operações com recursos do FGTS em 1990 e 1991, depois de quase três anos sem contratações de porte, caracteriza o governo Collor. Cerca de 95\% do total de investimentos em habitação popular nesses dois anos foram feitos através do FGTS. No entanto, a maneira como foram efetuadas as liberações de verba e as contratações acabou objeto de uma Comissão Parlamentar Mista de Inquérito, destinada a apurar irregularidades. Foram contratadas 526 mil unidades, 360 mil somente em 1991, volume que comprometeu o orçamento dos anos seguintes, impedindo a realização de novas operações. No final de 1996, contabilizavam-se 75 empreendimentos, com 26.553 unidades com características de empreendimentos-problema (Souza, 1998). Havia uma discrepância entre a baixa qualidade das habitações e a faixa de renda a quem se destinavam; muitas ficaram inacabadas e foram invadidas, por exemplo. Outras foram abandonadas ou 
permaneceram muito tempo sem ocupação por não terem uma demanda caracterizada, destinada a ocupá-las. Os motivos que levaram a isso foram vários, mas destacamos a má qualidade das habitações, a localização inadequada e os preços incompatíveis com a demanda que supostamente seria atendida (Freitas, 2002).

A instituição do financiamento direto à pessoa física e ao produtor dos imóveis ao invés da destinação de recursos para o empreendimento em si, desvinculado do futuro mutuário, foi uma das diferenças básicas que marcaram o período imediatamente pós-Collor. 0 programa Carta de Crédito Individual, criado em 1995 nessa lógica é, ainda hoje, o principal programa de aplicação de recursos do FGTS, sendo o veículo formal do Programa Minha Casa Minha Vida.

\section{Aspectos da evolução recente de títulos de base imobiliária no Brasil}

Títulos de base imobiliária podem ser caracterizados como papéis que contêm uma promessa de pagamento em um determinado prazo e com uma determinada remuneração cuja valorização e/ou fluxo de recursos se dá a partir de empreendimentos imobiliários. Os títulos creditícios não são criação recente, visto que são parte integrante do sistema bancário e parte fundamental do mercado de capitais. Porém suas transformações e metamorfoses e sua entrada na produção do parque imobiliário urbano nos ajudam a entender as tendências recentes da entrada da lógica das finanças no espaço construído das cidades.
Acompanhar criticamente a evolução dessas medidas de melhoria do ambiente institucional para o crédito imobiliário é relevante para se compreender os desenhos institucionais que daí advêm. A agenda de mudanças institucionais preconizadas pelas finanças globais (WB, 2002) no que concerne ao desenvolvimento do crédito imobiliário se insere nesse movimento. Melhoria do ambiente institucional, fortalecimento do mercado secundário de títulos, desburocratização dos processos relativos à concessão de crédito (para bons "pagadores", diga-se) são parte da agenda de organismos como o Banco Mundial.

Importante ressaltar que o mercado de títulos foi viabilizado modernamente no país depois das reformas conduzidas a partir do início dos anos 1990, na chamada flexibilização da economia, com a "retirada gradativa dos controles que obstaculizavam o livre fluxo internacional de capitais" (Paulani, 2012). 0 equacionamento da dívida externa brasileira por meio de sua securitização se insere nesse contexto, por exemplo. 0 Brasil caminhava para estabelecer sua posição no capitalismo financeirizado, absorvendo poupança externa e sendo uma opção atraente para o rentismo internacional (ibid.). Veremos adiante como essa inserção no capitalismo financeirizado produz efeitos nas políticas de infraestrutura e na atuação do Estado.

Não há como ignorar a importância do crédito e do fomento de mercados privados para o financiamento e promoção de políticas de infraestrutura, em especial da política habitacional. Apesar de parecer óbvio para os profissionais que atuam no âmbito do espaço e das ciências sociais aplicadas, a lógica que tem regido as políticas de crédito habitacional 
e imobiliário são lógicas economicistas não apenas no Brasil, mas também nos países ditos modelares por operadores do mercado imobiliário brasileiro: Espanha, México e Chile, por exemplo (Abecip, 2005).

Como se sabe, o padrão de financiamento da política habitacional brasileira pós-1964 esteve centrado no crédito lastreado na captação de poupança, tanto voluntária quanto compulsória e muito pouco no repasse de recursos orçamentários de origem fiscal. A constituição do SFH, nascido de uma conjuntura de intervenção do estado na economia, regulação de mercados e direcionamento de recursos onerosos a partir de critérios políticos é bastante distinta da formatação do Sistema Financeiro Imobiliário, criado em 1997 em pleno período de consecução do ajuste neoliberal no Brasil, que pressupõe a livre negociação entre as partes, limitando-se o estado a resolver as chamadas "falhas de mercado" (WB, 2002). Toda a argumentação de que falta um sistema de crédito destinado ao setor imobiliário, de que o setor será alavancado caso esse sistema funcione, vem ao encontro da edição da lei do SFI (Royer, 2014).

A habitação acabou virando um excelente pretexto para o discurso da alocação de recursos do SFH na promoção de produtos imobiliários em geral, por meio do ambiente financeiro do SFI. Na ocasião da criação deste sistema, não faltaram os que criticassem o SFH como ultrapassado, defendendo a sua substituição para que finalmente a questão habitacional fosse resolvida (Abecip, 2005). Mesmo que o SFH continue produzindo seus resultados, ainda resistem os que veem no modelo do SFI a grande oportunidade de combate ao déficit de moradias no Brasil (FGV, 2007).
Um dos instrumentos financeiros centrais na lei do SFI é o Certificado de Recebível Imobiliário. 0 CRI é um título de crédito nominativo, de livre negociação, lastreado em créditos imobiliários, constituindo promessa de pagamento em dinheiro. Apresenta forma escritural, de modo que seu registro e negociação devem ser feitos por sistemas centralizados de custódia e liquidação de títulos financeiros privados, sendo controlados pela CETIP (Central de Custodia e Liquidação Financeira de Títulos). São de emissão exclusiva das companhias securitizadoras. Podem ser lastreados em fluxos de recebíveis (pagamentos) de empreendimentos imobiliários específicos ou de um conjunto pulverizado de operações de crédito imobiliário.

Os CRI também compõem os ativos de fundos de investimentos, como dos Fundos de Investimento em Direitos Creditórios (FDIC) e dos Fundos de Investimentos Imobiliários (FII). Apesar de terem sido criados em 1993, sua regulamentação foi feita em 2008 por meio da Instrução CVM (Companhia de Valores Mobiliários) $n^{0} 472 .^{7}$ No caso especialmente dos FII, mas também no caso dos FIDC, seus ativos compreendem uma gama relativamente diversificada de instrumentos não necessariamente vinculados a operações de financiamento habitacional. Segundo o Portal do Investidor,

[...] de acordo com a regulação vigente, além de poder adquirir direitos reais sobre bens imóveis, o Fll pode também ter outros tipos de aplicações, tais como: letras de crédito imobiliário ( $\mathrm{LCl})$; letras hipotecárias (LH); cotas de outros Fll; certificados de potencial adicional de construção (Cepac); certificados de recebíveis imobiliários (CRI); cotas de fundos de investimento em direitos creditórios (FIDC) que tenham como política de investimento, 
exclusivamente, atividades permitidas aos Fll e desde que sua emissão ou negociação tenha sido registrada na CVM; além de valores mobiliários de emissores cujas atividades preponderantes sejam permitidas aos FII. (Brasil, CVM, 2013)

A partir das regulamentações desses instrumentos, em conjunto com outras medidas e o aumento da concessão do crédito ao setor imobiliário, o estoque de instrumentos do SFI cresceu sistematicamente depois do início de 2008, especialmente no caso dos CRI e das $\mathrm{CCl}$ (Cédulas de Crédito Imobiliário). Um fator importante na expansão desses mercados foi a disseminação das vendas desses títulos no segmento de varejo dos bancos. Inicialmente restritas a clientes de private banking, as aplicações em CRI exigiam um valor mínimo de R\$300 mil. Em 2011, o valor da aplicação mínima foi reduzido como uma forma de ampliar a distribuição desses títulos no varejo. A estratégia foi ensejada pela maior demanda de títulos de renda fixa diante da trajetória de queda das taxas de juros à época.
Já as operações com LCl (Letras de Crédito Imobiliário) cresceram, sobretudo, a partir do início de 2010, quando foram extintos os limites de aplicação nesses papéis para efeito de contabilização das exigibilidades do SFH. As LCI contam ainda com a isenção de Imposto de Renda e com cobertura do Fundo Garantidor de Crédito, ampliando sua atratividade junto aos investidores "pessoa física". Apesar do desempenho positivo desses instrumentos, é importante ressaltar que apenas uma parcela minoritária das operações concerne ao setor habitacional. Segundo dados do Anuário Estatístico da Uqbar, do total das emissões de CRI no ano de 2010 apenas 15\% estavam associadas a financiamentos habitacionais. Em 2011, essa participação mais do que dobrou, chegando a $36,7 \%$, mas permanecia ainda minoritária.

Os dados do estoque de operações de mercado de capitais que tem vinculação com o setor imobiliário mostram um crescimento expressivo do volume de recursos operados nesse mercado.

Tabela 1 - Estoque de títulos creditícios vinculados ao setor imobiliário

\begin{tabular}{l|c|c|c|c|c}
\hline \multirow{2}{*}{ Ano } & \multicolumn{5}{|c}{ Estoque - Vinculados ao setor imobiliário (R\$ milhões) } \\
\cline { 2 - 6 } & CCI & CRI & Letra hipotecária & LCI & Total \\
\hline 2006 & 2.011 & 2.170 & 3.283 & 7.283 & 14.746 \\
2007 & 2.636 & 2.867 & 1.955 & 7.844 & 15.303 \\
2009 & 8.287 & 7.208 & 1.045 & 10.503 & 27.043 \\
2010 & 12.703 & 10.567 & 3.727 & 15.510 & 42.508 \\
2011 & 24.295 & 18.919 & 1.896 & 29.260 & 74.371 \\
2012 & 43.790 & 27.795 & 2.024 & 46.832 & 120.441 \\
\hline
\end{tabular}

Fonte: Cetip (2013). Valores nominais. 
Ainda que não seja possível compará-lo em nível de grandeza com outros mercados de títulos (como os da dívida pública, por exemplo), o que chama atenção, em especial para o propósito deste estudo, é o crescimento desse mercado e o aumento significativo dos recursos que estão sendo movimentados em uma série histórica relativamente recente.

De fato, de um total de 14,7 bilhões de reais em 2006, o estoque desses títulos foi para mais de 150 bilhões de reais em 2012 (em valores nominais).

A análise macroeconômica do aumento do interesse do investidor por títulos que tenham isenção fiscal, características básicas de um investimento em renda fixa, e retorno condizente com a operação, pode ser aplicada a quase todos os títulos de base imobiliária. A queda da taxa básica de juros, também é apontada como um fator que obriga investidores de todo o tipo e tamanho a buscarem a rentabilidade em outro tipo de papéis e investimentos.
Esses são os principais pontos levantados por analistas de mercado ao se depararem com um crescimento tão significativo desses títulos de 2008 a 2012.8

Já o volume negociado nos mostra 0 crescimento do mercado secundário no Brasil com títulos de base imobiliária. Consegue-se aí identificar a importância crescente desse mercado secundário e o papel destacado do CRI pela sua natureza jurídica.

0 anuário da Uqbar, consultoria especializada em securitização imobiliária, apresenta 0 ano de 2012 como o momento

[...] mais profuso de nossa recente história em oportunidades que vão surgindo ao redor do mercado de títulos de securitização imobiliária e de segmentos correlatos. Dando sustentação a este ambiente construtivo, cresce com vigor o setor imobiliário no Brasil e, de forma paralela, quase todas as suas fontes de financiamento que possibilitam esta expansão. (Uqbar, 2012, p. 2)

Tabela 2 - Volume negociado de títulos creditícios vinculados ao setor imobiliário

\begin{tabular}{l|c|c|c|c|c}
\hline \multirow{2}{*}{ Ano } & \multicolumn{5}{|c}{ Volume negociado - Vinculados ao setor imobiliário (R\$ milhões) } \\
\cline { 2 - 6 } & CCI & CRI & Letra hipotecária & LCI & \multicolumn{1}{c}{ Total } \\
\hline 2006 & 11 & 256 & 6 & 2 & 275 \\
2007 & 305 & 238 & 26 & 2 & 570 \\
2008 & 1.584 & 516 & 161 & 103 & 2.365 \\
2009 & 1.502 & 1.623 & 224 & 915 & 4.264 \\
2010 & 1.258 & 4.067 & 158 & 1.348 & 6.831 \\
2011 & 2.285 & 10.912 & - & 1.724 & 14.921 \\
2012 & 1.387 & 14.688 & 239 & 3.592 & 18.695 \\
\hline
\end{tabular}

Fonte: Cetip (2013). Valores nominais. 
A estruturação complexa das operações, como FII adquirindo CRI, ou como CRI lastreados em outros CRI caracterizam esse novo ambiente. 0 que nos interessa destacar é a importância do papel do FGTS na primeira alavancagem de CRIs feita com os recursos do Fundo em 2008, gerando o desempenho esperado por seus operadores. Como veremos, os aportes do FGTS para compra de CRIs ou ainda em FIl se dá anualmente, configurando uma certeza de liquidez mínima para esse mercado. Em 2012 o volume de CRI emitido foi de 13,58 bilhões, "maior do que a soma das emissões de 2010 e 2009", segundo o Anuário Uqbar (Uqbar, 2012).

As explicações para esse desempenho nem sempre são diretas. Estão relacionadas à necessidade da busca por uma melhor performance em ambiente de juros baixos. 0 discurso da captação de recursos no mercado para se fazer frente ao déficit habitacional sempre aparece nas exposições de motivos e analises de conjuntura das possibilidades desses instrumentos financeiros (Abecip, 2005). No entanto, as mudanças regulatórias quanto ao direcionamento da poupança e o papel do FGTS na alavancagem desse mercado, são apontadas por analistas financeiros como fatores preponderantes no desempenho recente da emissão desses títulos, procurando estabelecer real e finalmente um mercado de securitização imobiliária no Brasil. 0 FGTS, no ano de 2011, adquiriu mais de três bilhões em CRI (aproximadamente 20\% das emissões daquele ano) tendo sido fundamental para o desempenho desse mercado naqueles anos. $A$ importância do FGTS na alavancagem de operações ligadas ao circuito financeiro do capital imobiliário vai se tornando clara, mantendo a captura de recursos regulados do fundo público para esse mercado. Segundo o mesmo documento da consultoria especializada em securitização imobiliária,

[...] a estrutura de mercado de capitais, tendo como investidor o FGTS, funcionou como um vaso comunicante entre alguns sistemas de financiamento imobiliário, como o próprio sistema com as regras específicas do FGTS, o Sistema Financeiro de Habitação (SFH) e o Sistema de Financiamento Imobiliário (SFI), fazendo com que os recursos de um sistema realimentassem outro sistema. (Uqbar, 2012)

Pela primeira vez, a maioria das operações de CRI foi realizada com lastro em crédito imobiliário em detrimento de locações. 0 mercado existente até então sempre esteve mais focado em operações corporativas, com base em contratos de locação atípica na modalidade build to suit.

Tal mudança se apresenta totalmente em linha com as alterações de mercado existentes e com a revogação da Resolução $n^{\circ}$ 3347/2006 do CMN que trata das normas sobre direcionamento dos recursos captados em depósitos de poupança pelas entidades integrantes do SBPE e pela Resolução $n^{\circ}$ 3932/2010 do CMN. A Resolução $n^{\circ} 3932$, dentre outras disposições e alterações, determinou que só seriam considerados CRI possíveis de serem incluídos no chamado "Mapa 4" das instituições financeiras aqueles que tivessem lastro em crédito imobiliário (excluindo expressamente a possibilidade, ate então existente, de inclusão de CRI com lastro em locações).

Ademais, a Resolução $n^{\circ} 3932$ dispôs que as instituições financeiras que realizassem as operações de cessão de suas carteiras de 
crédito imobiliário às companhias securitizadoras de créditos imobiliários e que fossem vinculadas à emissão de CRI, poderiam utilizá-los para fins do cumprimento das exigibilidades de manutenção de no mínimo $65 \%$ do montante captado em deposito de poupança em operações de financiamento imobiliário.

\section{Títulos de base imobiliária e o FGTS}

Ao que tudo indica, portanto, um "cliente" fundamental para o crescimento do mercado de títulos de base imobiliária é o FGTS. Uma série de resoluções do CMN e do CCFGTS, editadas praticamente ano a ano desde 1998, mostram que os CRI e outros títulos de mesma natureza foram ganhando espaço no mercado de capitais, ampliando sua participação na captação de recursos do FGTS que seriam destinados inicialmente para o atendimento a empreendimentos destinados à baixa renda.
Não é demais insistir ainda que o sucesso desses instrumentos contou com a legitimação, ao menos no nível do discurso, do déficit habitacional brasileiro. No entanto, a entrada do que seriam "novas" fontes de recursos para um setor "atrasado" ou ainda totalmente dependente da captação da poupança e do FGTS parece contraditória, visto que são justamente esses os recursos que se mostram fundamentais para girar o ciclo dos investimentos e tornar atrativos os títulos para os investidores.

0 desempenho do FGTS tem demonstrado o quão relevante é este fundo para a produção de habitação de interesse social. De 2008 a 2014, 231,2 bilhões de reais foram destinados para o financiamento à construção e à aquisição de imóveis, conforme Tabela 3. Ou seja, o Fundo tem hoje um papel fundamental na provisão de habitação para renda média e baixa no país. Magalhães Eloy demonstra que esse papel, no entanto, poderia ser ainda maior já que o gasto ainda estaria aquém da capacidade de investimento do FGTS (Magalhães Eloy, 2015).

Tabela 3 - Execução de itens do orçamento do FGTS 2008-2014

\begin{tabular}{c|c|c|c|c|}
\hline $\begin{array}{c}\text { Valores } \\
\text { em R\$ mil }\end{array}$ & \multicolumn{4}{|c|}{ Execução do Orçamento FGTS } \\
\hline Ano & Habitação & Descontos/subsídios & Saneamento básico & Infraestrutura \\
\hline 2008 & 13.590 .867 & 1.887 .114 & 4.438 .847 & - \\
2009 & 20.205 .413 & 3.971 .321 & 1.948 .801 & - \\
2010 & 33.241 .715 & 6.406 .883 & 553.129 & 5.300 .270 \\
2011 & 37.842 .316 & 6.444 .327 & 1.251 .620 & 1.782 .502 \\
2012 & 39.583 .015 & 7.511 .490 & 615.517 & 781.315 \\
2013 & 42.805 .021 & 8.494 .310 & 4.841 .437 & 3.717 .843 \\
2014 & 43.930 .537 & 7.896 .549 & 6.731 .361 & 6.209 .627 \\
\hline
\end{tabular}

Fonte: Agente Operador do FGTS. Valores atualizados para 2014 pelo IPCA. 
No entanto o FGTS tem sido usado também e cada vez mais para alavancar programas e posições de mercado. 0 argumento central contido nos documentos técnicos é de que a gestão do Fundo tem buscado a melhor rentabilidade possível para as necessárias aplicações financeiras, e que dessa forma o Fundo se mantém saudável e respondendo a todos os compromissos que tem, especialmente os compromissos com seus cotistas.

De acordo com entrevistas realizadas junto ao Agente Operador do FGTS e análise de documentos, houve pressão no âmbito do Conselho Curador desde a Resolução CCFGTS $n^{\circ} 578 / 2008$ para que fosse autorizada a utilização dos recursos do FGTS em operações imobiliárias feitas diretamente ou por meio de títulos de base imobiliária. Nessas operações estão incluídas as debêntures para grandes empresas com a condição de executarem unidades habitacionais e também compras de CRIs "performados", ou seja, CRIs com lastro em empreendimentos habitacionais, fundos de investimento imobiliários e investimentos especiais.

Desses investimentos especiais, um dos mais "especiais" é o Fundo Imobiliário Porto Maravilha. O FGTS foi autorizado a investir 3,5 bilhões de reais no fundo, sendo seu único cotista. O FII Porto Maravilha foi criado com o propósito de realizar negócios de natureza imobiliária na operação urbana do porto, segundo seu prospecto. É ainda o maior Fll do país e adquiriu todo o estoque de Cepacs da operação, visando utilizá-los para comprar participação nos empreendimentos imobiliários no seu perímetro (Pereira e Moschiaro, 2015). Ao adquirir todo o estoque de Cepac e por ser 0 único controlador do fundo, o FGTS controla também o tipo de empreendimento imobiliário a ser construído, a estratégia de negócios e a margem de retorno dos investimentos.

As resoluções do CCFGTS n ${ }^{\circ} 578 / 2008$, 602/2009, 637/2010, 681/2012, 702/2012, $725 / 2013$ foram editadas para regulamentar esse tipo de investimento, que cresceu significativamente durante o período 2008-2012. Em uma das resoluções, os "considerandos" 9 apontavam para a importância da alocação de recursos do FGTS nesse mercado:

Considerando que, além do financiamento tradicional, o FGTS vem incentivando o mercado secundário, que cresce no País, disponibilizando linhas de crédito para aquisição de direitos creditórios vinculados ao desenvolvimento de projetos no setor imobiliário;

Considerando que os investimentos do FGTS nesses ativos elevam o nível de liquidez do setor imobiliário;

Considerando que os recursos da linha de investimentos criada em 2008 para aquisição de cotas de Fundos de Investimentos Imobiliários - Flls, de Fundos de Investimento em Direitos Creditórios - FIDCs e de debêntures, com lastro em operações de habitação, no valor de $\mathrm{R} \$ 3.000 .000 .000,00$ (três bilhões de reais), já estão integralmente comprometidos com operações contratadas e em vias de contratação no âmbito do Agente Operador do FGTS;

Considerando que além dessas operações já viabilizadas, existe demanda adicional apresentada ao Agente Operador da ordem de R\$ 5.000.000.000,00 (cinco biIhões de reais) (...). (Brasil, MTE, CCFGTS $n^{0}$ 602/2009) (grifo próprio)

De fato, existia demanda adicional e, pela evolução dos números das chamadas operações de mercado, essa demanda foi irrigada com os recursos do FGTS, como se pode verificar pela Tabela 4. 
Tabela 4 - Estoque de títulos creditícios vinculados ao setor imobiliário

\begin{tabular}{c|c}
\hline Ano & $\begin{array}{c}\text { Aquisição de CRI + Aplicação de FI-FGTS }+ \\
\text { Carteira administrada - } \\
\text { Debêntures/FII/CRI/FIDC (Contratado) }\end{array}$ \\
\hline 2008 & 9.344 .058 \\
2009 & 7.576 .630 \\
2010 & 7.172 .104 \\
2011 & 8.246 .509 \\
2012 & 7.167 .361 \\
2013 & 2.401 .094 \\
2.907 .220 \\
\hline
\end{tabular}

Fonte: Agente Operador do FGTS. Valores atualizados para 2014 pelo IPCA.

Os dados das operações de mercado mostram um grande crescimento até 2012. Em 2008 as operações totalizavam mais de 9,3 biIhões de reais e em 2012, 7,2 bilhões de reais (valores atualizados para 2014).

De 2008 a 2012 os valores aplicados em operações de mercado foram sistematicamente maiores do que os alocados para subsídios habitacionais. A partir de 2013 essa curva se inverte, com o investimento em financiamentos habitacionais continuando a subir, assim como os subsídios. Uma das possibilidades para compreensão dessa inversão é a trajetória de subida da Selic a partir de 2013, e a chamada deterioração do ambiente fiscal do país que geraria uma crise de confiança. Também as incertezas quanto à continuidade de recursos para o programa MCMV e mudanças no ambiente econômico mundial podem ser compor a motivação para esse comportamento. Esses motivos impactariam o mercado imobiliário e consequentemente o mercado de títulos de base imobiliária.
Ainda que seja importante acompanhar essa trajetória mais recente das chamadas operações de mercado, percebe-se que desde a regulamentação do uso do FGTS nesse mercado de títulos imobiliários, outra forma de operacionalizar os recursos está acontecendo. Há uma injeção de recursos em investimentos que se caracterizam como rentáveis para o próprio Fundo, dinamizando um mercado imobiliário que abriria frentes de expansão em áreas da cidade que não seriam utilizadas sem um aporte de recursos públicos, como a área portuária do Rio de Janeiro. Reforça-se o caráter de colchão de liquidez que tem o Fundo, porém de forma diversificada, investindo diretamente também em operações de mercado. A lógica que perpassa esses investimentos é uma lógica de valorização dos investimentos, como não poderia deixar ser. Certamente é realizado com todas as normas prudenciais para um investimento desse tipo, mas o que vale observar é a atuação do FGTS como um player no mercado imobiliário e no mercado de títulos imobiliários, sendo 
Gráfico 2 - Evolução da taxa Selic 2008-2014

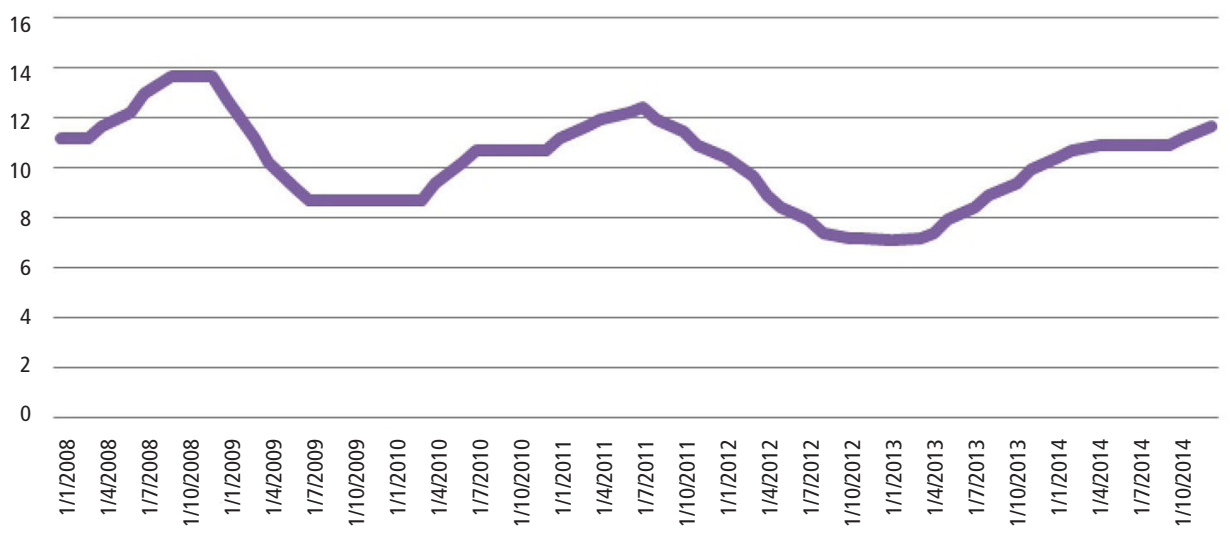

Série1

Fonte: Banco Central do Brasil. Elaboração própria.

Gráfico 3 - Evolução comparativa de recursos do FGTS:

Subsídio habitacional (Desconto) x Gastos em operações de mercado (título)

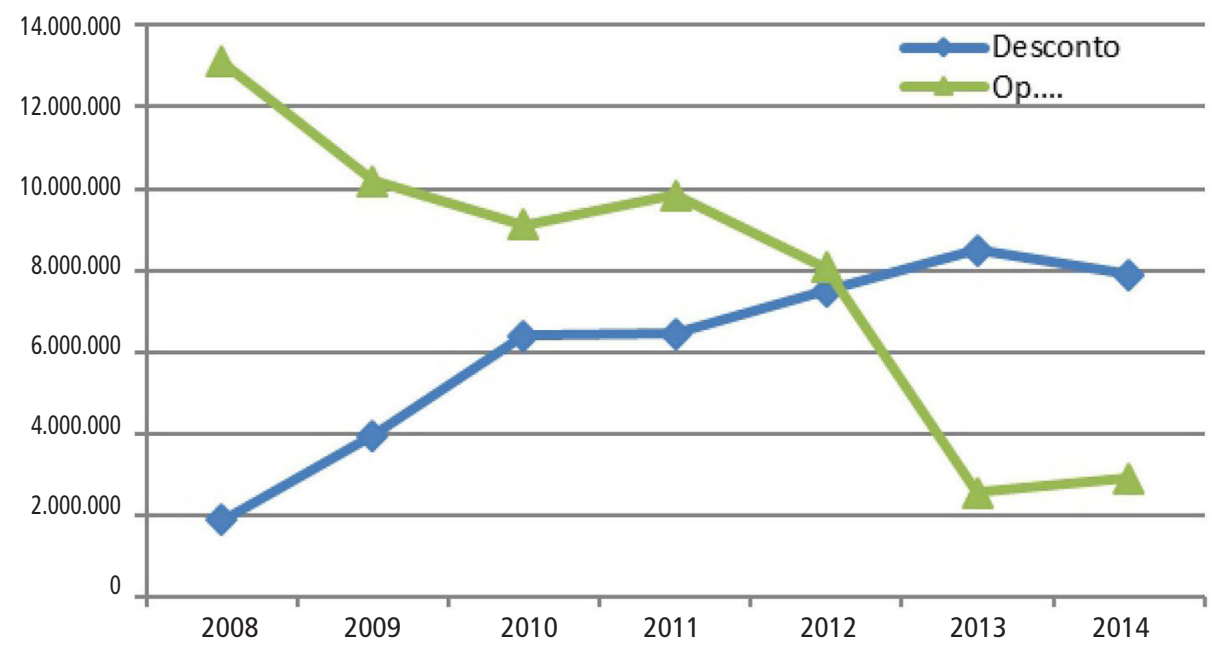

Fonte: Agente Operador do FGTS. Valores atualizados para 2014 pelo IPCA. Elaboração própria. 
decisivo na alocação de recursos, na escolha do tipo de investimento e de sua localização.

\section{Considerações finais}

Os fundos conhecidos como parafiscais (SBPE e FGTS) detém uma importância crucial para a promoção de politicas habitacionais desde sua criação ainda na década de 60. 0 FGTS, especialmente, tem um papel importante no acesso ao crédito para famílias de media e baixa renda. A forma de constituição desse fundo, uma poupança compulsória, e sua remuneração a taxas que podem variar abaixo de taxas inflação, tem se justificado pela importância da utilização de seus recursos na consecução de uma politica habitacional consistente e dirigida pelo Estado em um contexto de grande déficit, inadequação habitacional e de infraestrutura urbana.

Porém, e no contexto da inserção do país na atual etapa do modo de produção mundial centrado nas finanças, o FGTS tem proporcionado a criação e, de certo modo, a manutenção, de um mercado de títulos de base imobiliária. Esse colchão de liquidez e principalmente, a diminuição das incertezas e riscos pela compra antecipada e certa de títulos emitidos por companhias securitizadoras desses créditos, faz do FGTS um player importante nesse mercado. Nas operações de mercado do FGTS, constituídas pela aquisição de CRI, aplicação no Fundo de Investimento do FGTS (infraestrutura), debêntures, fundos de investimento imobiliário (entre eles o do Porto Maravilha) e fundos de direitos creditórios, o FGTS investiu de 2008 a 2014 aproximadamente 55,8 bilhões de reais. ${ }^{10} 0$ investimento tem sido justificado pelo fomento ao mercado imobiliário no país, que geraria empregos, e pela obtenção de rentabilidade para o próprio Fundo, garantindo sua saúde financeira. No entanto, como discutido anteriormente, o fomento se dá ao próprio mercado de títulos, ainda que a base imobiliária desses títulos movimente de certa forma a indústria da construção.

Nesse mesmo período, 231,2 bilhões de reais foram destinados a financiamentos habitacionais, mostrando a importância do FGTS para uma política publica de habitação, ao contribuir efetivamente para a construção de um parque habitacional. Para atingir faixas de renda média e baixa, a politica de subsídios do fundo destinou, também de 2008 a 2014, 42,6 bilhões de reais, o que foi fundamental para a viabilização dos empréstimos. Ainda que seja bastante relevante a discussão sobre o spread das operações do Fundo e o tipo de subsídios concedidos pelo FGTS (Magalhaes Eloy, 2015), não há como negar que a concessão de crédito e o subsídio conseguiram atingir um número significativo de famílias que estaria fora de qualquer possibilidade de crédito habitacional.

Porém ao viabilizar crescentemente as chamadas operações de mercado, o FGTS atua como um importante player nesse mercado, comportando-se como investidor institucional em um contexto de valorização dos títulos, buscando cada vez mais rentabilizar esses títulos.

Além de constituir-se em uma disputa pela utilização de seus recursos, os investimentos nessas operações de mercado de base imobiliária impacta a produção do espaço construído, a escolha e o tipo dos empreendimentos, sua localização, tendendo a promover e consolidar frentes de expansão imobiliária nas cidades. 
Ao buscar a valorização e a rentabilidade desses títulos nesse ambiente de negócios, o FGTS acaba por transformar os próprios cotistas do fundo em rentistas, como aponta Paulani:

Não é demais lembrar que é também o Estado que patrocina a distribuição de recursos dos trabalhadores para viabilizar a formação do grande capital, com a consequente geração de capital fictício que normalmente a acompanha. (...) transforma a classe trabalhadora como um todo em "rentista". Ainda que seus ganhos sejam magros, essa posição a obriga a torcer para o capital e, mais ainda, para o capital fictício, que afinal é gerido pelos próprios trabalhadores. (Paulani, 2012, p. 14)

0 controle social de fato sobre esses recursos e sua utilização parece ser um debate importante a ser feito, no contexto da construção de uma política pública de universalização de direitos.

\section{Luciana de Oliveira Royer}

Universidade de São Paulo, Faculdade de Arquitetura e Urbanismo. São Paulo/SP, Brasil. luroyer@gmail.com

\section{Notas}

(1) Relatório de Economia Bancária e Crédito, publicação anual do Banco Central do Brasil (BCB). Até o conclusão deste artigo, o Relatório de 2013 era o mais recente a ser disponibilizado.

(2) Depois da criação do FGTS em 1966, era facultado ao trabalhador escolher entre a poupança voluntária ou o regime de estabilidade obrigatório após 10 anos de contrato de trabalho. Ao empregador era obrigatório, após a opção do empregado, o recolhimento mensal de $8 \%$ do salário do empregado. Depois da Constituição de 88, o FGTS consolidou-se como um direito social e a estabilidade após de 10 anos de emprego foi extinta.

(3) Lei no 4.864, de 29 de novembro de 1965, que cria medidas de estímulo à Indústria de Construção Civil. As citações entre aspas a seguir no texto são de excertos da referida lei.

(4) Atualmente o FGTS é regido pela Lei no 8.036, de 11 de maio de 1990, e regulamentado pelo Decreto no 99.684, de 8 de novembro de 1990. Dados obtidos nos relatórios de gestão do FGTS disponíveis em www.caixa.gov.br/fgts.

(5) Constituem, ainda, recursos do Fundo: dotações orçamentárias específicas; resultados das aplicações dos recursos do FGTS; multas, correção monetária e juros moratórios devidos; receitas oriundas da Lei Complementar no 110/01; demais receitas patrimoniais e financeiras. 
(6) Sobre o FGTS é importante ainda salientar que o objetivo do Fundo, expresso na lei que atualmente o regulamenta é: (1) assegurar ao trabalhador optante a formação de um pecúlio relativo ao tempo de serviço em uma ou mais empresas, para ampará-lo em caso de demissão e a seus dependentes em caso de falecimento; e (2) fomentar políticas públicas por meio do financiamento de programas de habitação popular, de saneamento básico e de infraestrutura urbana. As normas e diretrizes do FGTS são estabelecidas por seu Conselho Curador, órgão tripartite, composto atualmente por oito integrantes de órgãos e entidades do Governo Federal, quatro representantes dos trabalhadores e quatro representantes dos empregadores. O agente gestor do FGTS é o Ministério do Trabalho e Emprego, a gestão da aplicação dos recursos do FGTS é efetuada pelo Ministério das Cidades, cabendo à Caixa Econômica Federal o papel de Agente Operador. A Caixa Econômica Federal é também Agente Financeiro do FGTS, partilhando essa função com outras instituições (bancos).

(7) Definição que consta de publicação da CVM destinada ao público em geral acessível em http://www.portaldoinvestidor.gov.br/portaldoinvestidor/export/sites/portaldoinvestidor/ publicacao/serie_guias/CVM-Guia-01-FII.pdf

(8) Entrevista feita com analista da Anbima, em setembro de 2013.

(9) Os "considerandos" são conhecidos por ser na técnica legislativa um resumo da exposição de motivos de uma lei. Como se trata de uma resolução e não de uma lei, os "considerandos" adquirem força explicativa do motivo da edição daquela resolução.

(10) Em valores de 2014 atualizados pelo IPCA, de acordo com a tabela apresentada. As agregações apresentadas na sequência também são atualizadas para 2014 pelo IPCA.

\section{Referências}

AALBERS, M. (2012). Subprime cities: The political economy of mortgage markets. London, John Wiley \& Sons.

ABECIP (2007). As contribuições dos sistemas imobiliários da Espanha e do México para o aperfeiçoamento do modelo brasileiro. In: SEMINÁRIO INTERNACIONAL DE CRÉDITO IMOBILIÁRIO. Anais. Rio de Janeiro, Abecip/Publitetto.

ABECIP; CBIC (2005). Primeira Revisão Trimestral da Proposta Acordada entre a ABECIP - Associação Brasileira das Entidades de Crédito Imobiliário e a CBIC - Câmara Brasileira da Indústria da Construção. Disponível em: http://www.cbic.org.br/arquivos/acordoABECIPCBIC.pdf.

ACCENTURE (2007). Crédito Imobiliário: Propostas para torná-lo um efetivo instrumento promotor do desenvolvimento econômico e social do país. In: CONFERÊNCIA INTERNACIONAL DE CRÉDITO IMOBILIÁRIO. Anais. Salvador/Brasília, Banco Central do Brasil.

ARAGÃO, J. M. (2005). Sistema financeiro da habitação: uma análise sócio-jurídica da gênese, desenvolvimento e crise do sistema. Curitiba, Juruá.

ARANTES, P. F. (2004). O ajuste urbano: as políticas do Banco Mundial e do BID para as cidades latino-americanas. Tese de Doutorado. São Paulo, Universidade de São Paulo. 
BRASIL. Ministério da Fazenda/Comissão de Valores Mobiliários (2012). Guia de Fundos de Investimento Imobiliários. Brasília, MF.

BRASIL. Ministério da Fazenda/Comissão de Valores Mobiliários (2013). Guia CVM do Investidor Fundos de Investimento Imobiliário 2012. Disponivel em: http://www.portaldoinvestidor.gov.br/ portaldoinvestidor/export/sites/portaldoinvestidor/publicacao/serie_guias/CVM-Guia-01-FII. pdf. Acesso em: 12 out 2015.

BRASIL. FGTS. CCFGTS. CEF (2015). Demonstrações Financeiras do FGTS - Relatório de Administração do FGTS - Exercício 2014. Disponível em: www.caixa.gov.br/fgts.

(2015a). Relatório de Gestão do Fundo de Garantia do Tempo de Serviço - Exercício 2014. Disponível em: www.caixa.gov.br/fgts.

CHESNAIS, F. (2005). "O Capital Portador de Juros: acumulação, internacionalização, efeitos econômicos e político". In: CHESNAIS, F. (org.). A Finança Mundializada: raízes sociais e políticas, configuração, consequências. São Paulo, Boitempo.

FGV - FUNDAÇÃO GETÚLIO VARGAS (2007). O Crédito Imobiliário no Brasil - Caracterização e Desafios. São Paulo, FGV-Projetos.

FIX, M. (2011). Financeirização e transformações recentes no circuito imobiliário no Brasil. Tese de doutorado. Campinas, Universidade Estadual de Campinas.

FREITAS, E. L. H. (2002). Como qualificar conjuntos habitacionais populares. Dissertação de Mestrado. Campinas, Pontifícia Universidade Católica de Campinas.

GOTHAM, K. F. (2012). "Creating Liquidity out of spatial fixity: The secondary circuit of capital and the restructuring of the US Housing Finance System". In: AALBERS, M. Subprime cities: the political economy of mortgage markets. London, John Wiley \& Sons.

HARVEY, D. (1982). O trabalho, o capital e o conflito de classes em torno do ambiente construído nas sociedades capitalistas avançadas. Revista Espaço \& Debates. São Paulo, n. 6, pp. 7-14.

(2005). A produção capitalista do espaço. São Paulo, Annablume.

LIMA JR., J. R. (1997). Fundos de Investimento Imobiliário, com Portfólio de Base imobiliária: Notas sobre a Depreciação do Ativo. Boletim Técnico do Departamento de Engenharia de Construção Civil. São Paulo, Escola Politécnica/Universidade de São Paulo, BT/PCC/187.

(2008). Evolução e Inovação: reflexões para empresas de Real Estate. Carta do NRE-POLI. São Paulo, Escola Politécnica/Universidade de São Paulo, n. 9-07.

MAGALHÃES ELOY, C. M. (2015). O potencial do SFH para a expansão do acesso à moradia no Brasil. In: XVI ENCONTRO NACIONAL DA ANPUR. Anais. Belo Horizonte.

MARICATO, E. (1979). A produção capitalista da casa (e da cidade) no Brasil Industrial. São Paulo, AlfaÔmega.

(1987). Política habitacional no regime militar. Petrópolis, Vozes.

(1996). Metrópole na periferia do capitalismo. São Paulo, Hucitec.

(2001). Brasil, cidades: alternativas para a crise urbana. São Paulo, Vozes.

MASSONETO, L. F. (2006). O direito financeiro no capitalismo contemporâneo: a emergência de um novo padrão normativo. Tese de Doutorado. São Paulo, Universidade de São Paulo. 
PAULANI, L. M. (2012). A inserção da economia brasileira no cenário mundial: uma reflexão sobre a situação atual à luz da história. Boletim de Economia e Política Internacional. Brasília, IPEA.

PEREIRA, A. e MOSCIARO, M. (2015). Urban redevelopment, public land and speculation: strategies and conflicts, Porto Maravilha - Rio de Janeiro. In: RC21 CONFERENCE, URBINO. Anais. Disponível em: http://www.rc21.org/en/wp-content/uploads/2014/12/C1-2-PEREIRA-MOSCIARO.pdf

ROYER, L. (2014). Financeirização da política habitacional: limites e perspectivas. São Paulo, Annablume.

SCHVASBERG, B. (1993). Atores em movimento na disputa territorial do FGTS nos anos 90: estado, espaço social e planejamento em transformação. In: V ENCONTRO NACIONAL DA ANPUR. Anais. Belo Horizonte.

SOUZA, M. T. X. (1998). Relatório da política habitacional 1991-1996. Trabalho Programado 2. Curso de pós-graduação FAU-USP. São Paulo, Mimeo.

UQBAR (2012). Anuário de Securitização e Financiamento Imobiliário 2012. Disponível em: http:// www.uqbar.com.br/institucional/oque/anuario_FI_12.jsp\#anuario. Acesso em: 20 fev 2013.

WORLD BANK (2000). Cities in Transition: World Bank Urban and Local Government Strategy. Washington, The World Bank.

(2002). Building Institutions for Markets. Nova York, Oxford University Press.

(2003). Housing finance in emerging markets: policy and regulatory challenges. Material relativo a curso promovido pelo Departamento de Operações e Políticas do Setor Financeiro do Banco Mundial. Washington, The World Bank.

Texto recebido em 7/nov/2015 Texto aprovado em 12/dez/2015 
